\title{
KJCCM
}

Korean J Crit Care Med

2017 November 32(4):363-369 / https://doi.org/10.4266/kjccm.2016.00073

ISSN 2383-4870 (Print) · ISSN 2383-4889 (Online)

\section{Methidathion Poisoning}

\author{
Ki Hoon Kim', Se Hun Kim², and Charles Her $^{2}$ \\ ${ }^{1}$ Department of Surgery, ${ }^{2}$ Department of Anesthesiology, Inje University Haeundae Paik Hospital, Inje University College of Medicine, Busan, Korea
}

\begin{abstract}
Although methidathion is an organophosphate insecticide, it is different from the other organophosphates in terms of toxicity. Because of its relatively high fat solubility, the apparent volume of methidathion distribution throughout the body is very high, indicating that hemoperfusion is not effective in removing this organophosphate from the body. Redistribution of methidathion from fat to blood can also occur when plasma levels diminish. Additionally, acetylcholinesterase aging, which is the loss of an alkyl side chain that prevents reactivation by oximes, is very rapid so that the effective reactivation by oximes is thwarted. Thus, methidathion's effect on acetylcholinesterase inhibition is long lasting, particularly with a high dose. In addition to its parasympatholytic effect and ability to induce muscle paralysis, methidathion poisoning is associated with a profound and long-lasting circulatory collapse due to sympathetic ganglion blockade. This report presents the case of a 55-year-old man who accidentally ingested a high dose of methidathion. He later developed enteroinvasive aspergillosis infection-induced multiple bowel perforations on two separate occasions while on mechanical ventilator support, resulting in a fatal outcome. The renin-angiotensin axis activated by sympathetic ganglion blockade may have reduced the patient's splanchnic blood flow, contributing to translocation of endotoxin. Also, the effect of excessive acetylcholine on non-neuronal acetylcholine receptors may have contributed to the development of fatal enteroinvasive aspergillosis in this patient.
\end{abstract}

Key Words: acetylcholine; aspergillosis; ganglia, sympathetic; organophosphate poisoning.

Methidathion, S-(5-methoxy-2-oxo-2,3-dihydro-1,3,4-thiadiazol-3-yl) methyl O,O-dimethyl phosphorodithioate, is a phosphorus ester used as an insecticide and an acaricide. Methidathion in itself is a poor cholinesterase inhibitor and it requires oxidation of the $\mathrm{P}-\mathrm{S}$ bond to become active [1]. Unlike other organophosphate insecticides, for the poisoning of which administration of parasympatholytic agents and mechanical ventilator support are the mainstay of management, sympathetic ganglion blockade by methidathion can be profound and long-lasting. This sympathetic ganglion blockade activates renin-angiotensin axis, which produces a tremendous change in splanchnic blood flow [2]. A decrease in splanchnic blood flow allows bacterial and endotoxin translocation via gastrointestinal mucosa [3]. The presence of splanchnic ischemia can increase possibility of developing an invasive biofilm-producing fungal infection such as aspergillosis. Catecholamine inotropes, which are used to overcome septic shock or hypotension, would stimulate the growth and biofilm formation of biofilm-forming bacteria and fungus [4-6]. In addition, the effects of excessively accumulated acetylcholine on non-neuronal nicotinic acetylcholine receptors, including alpha-7 nicotinic receptor on

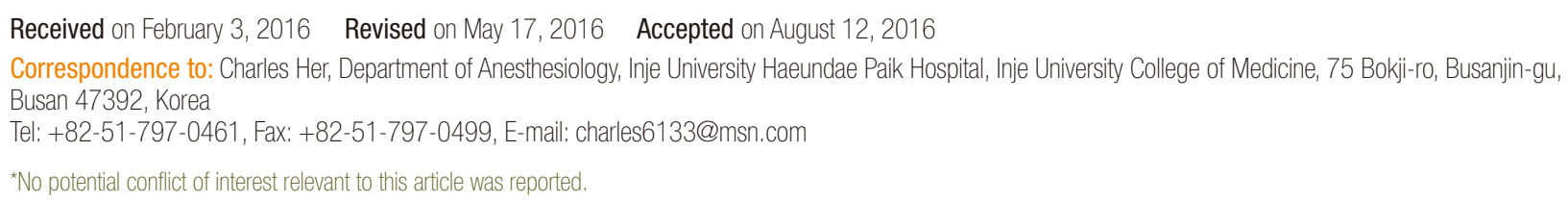

cc This is an Open Access article distributed under the terms of the Creative Commons Attribution Non-Commercial License (http://creativecommons.org/ licenses/by-nc/4.0/) which permits unrestricted non-commercial use, distribution, and reproduction in any medium, provided the original work is properly cited. Copyright (c) 2017 The Korean Society of Critical Care Medicine 
proximal immune cells [7], and the effects of high doses of parasympatholytic drugs, which are used to overcome severe bradycardia, on the non-neuronal muscarinic acetylcholine receptor in the biofilm-producing fungus [8] would contribute to the increase in the chance of biofilmforming fungal infection. In diabetic patients with methidathion poisoning, the fatal outcome from secondary infection of biofilm-forming organism may be inevitable.

\section{Case Report}

A 55-year-old man was brought to emergency room after accidental ingestion of insecticide, methidathion (also known as methion in Korea) while he was drunken. According to his family member, he ingested a paper cup full of $40 \%$ original solution. He had history of noninsulin dependent diabetes mellitus. His body weight was $75 \mathrm{~kg}$ and height was $173 \mathrm{~cm}$.

In the emergency room, he was semi-comatose, but had intermittent myoclonus-like movements. Blood pressure was $67 / 50 \mathrm{mmHg}$ and heart rate was 48 beats per minute. His trachea was intubated and he was placed on mechanical ventilation. Initial resuscitation efforts included intravenous infusion of atropine ( $50 \mathrm{mcg} / \mathrm{min})$ after a bolus of $1 \mathrm{mg}$, norepinephrine $(0.25 \mathrm{mcg} / \mathrm{kg}$ of body weight $/ \mathrm{min})$, vasopressin ( 0.3 units $/ \mathrm{min})$, dobutamine $(30 \mathrm{mcg} / \mathrm{kg} / \mathrm{min})$, epinephrine $(0.25 \mathrm{mcg} / \mathrm{kg} / \mathrm{min})$, and PAM-A (pralidoxime chloride, cholinesterase reactivator, $2.5 \mathrm{mg} / \mathrm{min}$ ), in addition to intravascular volume expansion with crystalloids, in efforts to keep the mean arterial pressure higher than $65 \mathrm{mmHg}$. Also given were midazolam, remifentanyl, and vecuronium. Gastric lavage was done. The initial arterial blood gas analysis while he was being mechanically ventilated with $100 \%$ of oxygen showed that $\mathrm{pH}$ was 6.96 , $\mathrm{PCO}_{2} 98 \mathrm{mmHg}, \mathrm{PO}_{2} 85 \mathrm{mmHg}, \mathrm{HCO}_{3}^{-} 19 \mathrm{mEq} / \mathrm{L}$, and $\mathrm{BE}-14.8$. His ethanol level in blood was $144 \mathrm{mg} / \mathrm{dl}$. Albumin was $4.4 \mathrm{~g} / \mathrm{dl}$, glucose $359 \mathrm{mg} / \mathrm{dl}$, Hemoglobin Alc $11.4 \%$, and total $\mathrm{CO}_{2}$ content $16.9 \mathrm{mEq} / \mathrm{L}$. The levels of total bilirubin, aminotransferases, sodium, chloride, potassium and troponin I were normal, so were prothrom- bin time, international normalized ratio, and activated thromboplastin time. Leukocyte count was 17,400 cells/ $\mathrm{mm}^{3}$, hemoglobin $15.4 \mathrm{~g}$, hematocrit $46 \%$ and platelets $266,000 / \mathrm{mm}^{3}$. The repeated analysis of arterial blood gases showed that $\mathrm{pH}$ was 7.09, $\mathrm{PCO}_{2} 29 \mathrm{mmHg}, \mathrm{PO}_{2} 66$ $\mathrm{mmHg}, \mathrm{HCO}_{3}^{-} 20 \mathrm{mEq} / \mathrm{L}, \mathrm{BE}-11.3$ and lactate $7.8 \mathrm{mEq} /$ L. Urine output had been in the range of 200 to $600 \mathrm{ml} / \mathrm{h}$. Serum cholinesterase level was 12 (normal, 620-1,370) units/L.

The patient was transferred to intensive care unit. Tests for hepatitis A, B, and C were negative, so was human immunodeficiency virus test. Free $\mathrm{T}_{4}$ level was $3.84 \mathrm{mcg} /$ L. Arterial blood gases showed that $\mathrm{pH}$ was $7.23, \mathrm{PCO}_{2}$ $59 \mathrm{mmHg}, \mathrm{PO}_{2} 78 \mathrm{mmHg}, \mathrm{HCO}_{3}^{-} 24 \mathrm{mEq} / \mathrm{L}$ and lactate $1.7 \mathrm{mEq} / \mathrm{L}$. Blood cultures, of which blood samples were taken from the central venous line, arterial line and percutaneous punctures, were all negative. Intravenous infusion of vecuronium was discontinued. On the 2 nd hospital day, intravenous infusion of epinephrine was tapered off. The infusion of norepinephrine was reduced to $0.15 \mathrm{mcg} /$ $\mathrm{kg} / \mathrm{min}$, vasopressin to 0.15 units $/ \mathrm{min}$ and dobutamine to $20 \mathrm{mcg} / \mathrm{kg} / \mathrm{min}$. There was no longer metabolic acidosis. Urine output decreased to $300 \mathrm{ml} / \mathrm{h}$. On the 4 th hospital day, intravenous infusion of atropine was discontinued. Glycopyrrolate was given intermittently whenever heart rate became less than 60 beats per min. Urine output was running about $100 \mathrm{ml} / \mathrm{h}$. Daily chest radiography had been unremarkable. Sputum culture revealed the growth of Klebsiella pneumoniae, which was sensitive to all antibiotics except ampicillin. Piperacillin/tazobactam was started. On the 5th hospital day, doses of vasopressors and inotropic were not able to be reduced. Interleukin- 6 was $335 \mathrm{pg} /$ $\mathrm{ml}$ and procalcitonin $92 \mathrm{ng} / \mathrm{ml}$. Intravenous infusion of remifentanil and midazolam had been maintained for sedation. Despite the use of high doses of vasopressors and inotropic, the patient's hands and feet were warm and pink, and there was no metabolic acidosis, thus indicating that there was no peripheral vasoconstriction or poor peripheral perfusion. On the 6th hospital day, lactate level was 1.3 $\mathrm{mEq} / \mathrm{L}$. Fibrinogen was $966 \mathrm{mg} / \mathrm{dl}$ and d-dimer $6.53 \mathrm{mg} / \mathrm{L}$. The absence of deep vein thrombosis was confirmed with 
ultrasonography and transthoracic echocardiography ruled out an acute pulmonary embolism (no right ventricular dysfunction). Total parenteral nutrition was started. Enteral feeding was not considered appropriate at this time. On the 9th hospital day, intravenous midazolam infusion was discontinued. Over the following several days, vasopressors and inotropic were able to be reduced gradually. On the 11th day, all vasoactive medications were completely tapered off. The patient opened eyes on command. Intravenous infusion of ketamine was added. On the 14th hospital day, ulnar nerve stimulation test using train-of-four technique to assess neuromuscular junction activity revealed the presence of depolarizing block, indicating the persistent muscle paralysis by cholinergic crisis. Sputum culture showed the growth of methicillin-resistant Staphylococcus aureus. Vancomycin was started. On the 17th hospital day, $\mathrm{pH}$ of arterial blood decreased 7.29 from 7.41 and $\mathrm{PCO}_{2}$ increased to $56 \mathrm{mmHg}$ from $42 \mathrm{mmHg}$ in the afternoon, compared with those of morning values. Leukocyte count increased to 17,750 cells $/ \mathrm{mm}^{3}$ from 12,000. Platelet count also increased to $765,000 / \mathrm{mm}^{3}$ from $576,000 / \mathrm{mm}^{3}$. Ultrasonography of abdomen showed a large amount of ascites. CT scan of abdomen revealed multiple perforations of small bowel. While the exploratory laparotomy was being arranged, pulmonary artery catheter was inserted via right subclavian vein under ultrasonographic guidance. Pulmonary artery pressure was $36 / 18 \mathrm{mmHg}$ with pulmonary capillary wedge pressure of $12 \mathrm{mmHg}$. On laparotomy, almost the whole small bowel was found gangrenous and there were multiple perforations of small bowel. The portion of bowel from the distal duodenum to the ascending colon was resected. Since there was no gross evidence of peritonitis, the peritoneum was closed. Postoperatively, vasopressors and inotropic were required overnight, but quickly tapered off by the following morning. Urine output was running in the range of 100 to $300 \mathrm{ml} / \mathrm{h}$. Analysis of arterial blood gases showed that $\mathrm{pH}$ was 7.44, $\mathrm{PCO}_{2} 44$ $\mathrm{mmHg}, \mathrm{PO}_{2} 83 \mathrm{mmHg}$ and $\mathrm{HCO}_{3}^{-} 29.2 \mathrm{mEq} / \mathrm{L}$, while the patient was on mechanical ventilator with $10 \mathrm{cmH}_{2} \mathrm{O}$ and 0.6 of $\mathrm{FiO}_{2}$. Lactate was $1.8 \mathrm{mEq} / \mathrm{L}$. Creatinine was 1.15 $\mathrm{mg} / \mathrm{dl}$. Leukocyte count was 17,690 cells $/ \mathrm{mm}^{3}$ and platelet
352. Fibrinogen level was $305 \mathrm{mg} / \mathrm{dl}$. On the 20th hospital day, glycopyrrolate was given for the last time. Cultures from the peritoneal drain and blood were all negative. Procalcitonin was $5.03 \mathrm{ng} / \mathrm{dl}$, interleukin-6 $92.2 \mathrm{pg} / \mathrm{dl}$, Creactive protein 16.32 , fibrinogen $432 \mathrm{mg} / \mathrm{dl}$ and platelet count $230,000 / \mathrm{mm}^{3}$. Repeated ulnar nerve stimulation test using train-of-four technique revealed the presence of depolarizing block, indicating the persistent muscle paralysis by cholinergic crisis. Pathologic report of surgical specimen revealed the aspergillosis infection causing gangrene and abscess formation with multiple bowel perforations. Serum Aspergillus antigen (galactomannan) was negative. Voriconazole was started. On the 27th hospital day (10th postoperative day), culture of peritoneal drain fluid showed the growth of methicillin-resistant $S$. aureus. Blood culture was negative. On the 31st hospital day, the second laparotomy revealed a diffuse peritonitis, gangrenous colon and abscess formation with perforations. Total colectomy was done. Postoperatively, the patient developed a severe septic shock, requiring vasopressors and inotropic in escalating doses. Intravascular volume expansion was done with guidance of pulmonary artery catheter. Thermodilution cardiac output was running in the range of 10 to $12 \mathrm{~L} / \mathrm{min}$. The patient developed a severe metabolic acidosis with rising level of lactate. On the 38th hospital day, lactate level rose to $10.7 \mathrm{mEq} / \mathrm{L}$. Repeated test for Aspergillus antigen (galactomannan) became positive (5.42 index). The patient developed a sudden cardiac arrest. A prolonged effort of cardiopulmonary resuscitation became futile.

\section{Discussion}

Compared with other organophosphate insecticides, methidathion appears to be the most dangerous organophosphate substance in producing toxicity such as a prolonged muscle paralysis requiring mechanical ventilator support, profound circulatory collapse requiring high doses of vasopressors and inotropics, severe bradycardia requiring high doses of parasympatholytic agents, and 
secondary enteroinvasive fungal infection.

Acetylcholine is regarded as a classical neurotransmitter (neuronal cholinergic). Nicotinic acetylcholine mediates chemical neurotransmission at neurons, ganglia, interneurons and the motor endplate. Nicotonic receptors are ligand-gated ion channels, when bound to acetylcholine, these receptors undergo a conformational change that allows the entry of sodium ions, resulting in the depolarization of the effector cell. In the presence of acetylcholinesterase inhibitor such as organophosphate, acetylcholine is accumulated at the nicotinic receptor, resulting in the continuous depolarization of effector cell, thus leading into dysfunction of the effector cell or organ. Dysfunction of this neuronal cholinergic system causes central nervous system disorders, such as coma and seizure, sympathetic ganglion blockade leading to circulatory collapse, and the motor endplate dysfunction resulting in muscle paralysis. Muscarinic acetylcholine mediates chemical neurotransmission at neurons and effector organs such as heart, smooth muscle fibers and glands. Muscarinic receptors are G-protein coupled receptors. Thus, the accumulated acetylcholine at muscarinic receptor, in the presence of acetylcholinesterase inhibitor, results in the augmented agonistic effect (parasympathetic) on the effector cell or organ.

The preganglionic neuron for sympathetic ganglion is cholinergic and the acetylcholine receptor on postganglionic neuron is nicotinic. In the presence of acetylcholinesterase inhibitor, the accumulated acetylcholine induces cholinergic crisis, resulting in sympathetic ganglion blockade, thus leading to circulatory collapse. Surprisingly, in this patient of the present case report, the effect of sympathetic ganglionic blockade was so profound that the patient required very high doses of vasopressors and inotropic agent for a prolonged period, to maintain mean arterial pressure at the level of $65 \mathrm{mmHg}$ or higher, despite an aggressive intravascular volume expansion. Although there was no evidence of poor peripheral blood flow or metabolic acidosis while high doses of vasopressors and inotropic agent were running, the possibility of a decrease in splanchnic blood flow could not be excluded.
Because of the pathophysiologic prioritization of systemic over local splanchnic hemodynamic needs, the response of the splanchnic vasculature to circulatory shock leads to splanchnic organ ischemic injury. The selectively decrease in splanchnic blood flow induced by circulatory shock is a direct consequence of the hypersensitivity of the splanchnic vasculature to the renin-angiotensin axis as shown in Figure 1 [2]. As such, the absence of metabolic acidosis in systemic circulation may not exclude the possibility of suboptimal splanchnic perfusion which can be reflected by low gastrointestinal intramucosal $\mathrm{pH}$ [9]. A decrease in splanchnic blood flow allows bacterial and endotoxin translocation via gastrointestinal mucosa, leading to endotoxemia. This endotoxemia may explain increases in inflammatory markers such as interleukin 6 , procalcitonin and C-reactive protein on the 5 th hospital day. Thus, the patient in the present case report may have had splanchnic ischemia, which could have contributed to a rapid progression of enteroinvasive aspergillosis.

The use of catecholamine may promote the growth of biofilm-forming bacteria and fungus. Catecholamine inotropes such as norepinephrine and epinephrine have been

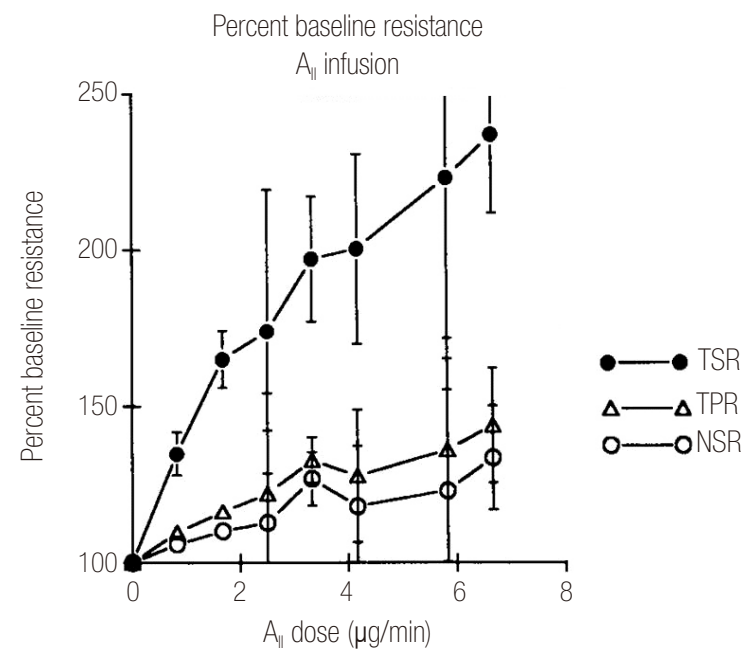

Figure 1. Responses to angiotensin II $\left(A_{\|}\right)$infusion. The splanchnic vascular bed responds selectively by disproportionate vasoconstriction to a central intravenous infusion of angiotensin II, mimicking its response to cardiogenic shock. TSR: total splanchnic vascular resistance; TPR: total peripheral vascular resistance; NSR: non-splanchnic vascular resistance. Adapted from Reilly and Bulkley. Crit Care Med 1993;21(2 Suppl):S55-68, with permission of Lippincott Williams \& Wilkins [2]. 
shown to be potent stimulators of growth and film formation of Pseudomonas aeruginosa [4] and Staphylococcus species [5], via a mechanism involving inotrope delivery of transferrin ion, internalization of inotrope, and upregulation of the key pseudomonal siderophore pyoverdine, which is a mechanism to increase uptake of iron from transferrin by bacteria for growth and biofilm formation. Aspergillus species use the similar mechanism including siderophore system to increase iron uptake for growth and biofilm formation [6]. As such, catecholamine inotrope should be able to stimulate the formation of biofilm by Aspergillus fungus. Thus, it is most likely that the prolonged use of high doses of catecholamine inotropes in effort to overcome the profound hypotension in the patient of the present report would have contributed to the development of enteroinvasive aspergillosis, independent of their effects on splanchnic perfusion. Interestingly, the culture of peritoneal fluid after first bowel perforation showed the growth of biofilm-forming $S$. aureus instead of Gram-negative bacteria, thus supporting the abovementioned argument.

Cholinergic signaling in non-neuronal cells is comparable to cholinergic neurotransmission. In mammalian non-neuronal cells, including those of humans, all components of the cholinergic system such as choline acetyltransferase, acetylcholine, nicotinic and muscarinic acetylcholine receptors have been demonstrated. Blockade of nicotinic and muscarinic acetylcholine receptors on non-innervated cells causes cellular dysfuncftion and/ or cell death. The cholinergic anti-inflammatory pathway regulates immune responses to pathogens and is mediated by acetylcholine, involving the alpha-7 nicotinic receptors on proximal immune cells [7], although investigations into the role of the cholinergic anti-inflammatory pathway in bacterial infections have shown contradictory findings. It is most likely that the blockade of non-neuronal nicotinic acetylcholine receptors by organophosphate like methidathion would allow cholinergic proinflammatory pathway to be activated. Furthermore, a previous study has demonstrated that the acetylcholine protects against Candida albicans infection by inhibiting biofilm formation and promoting hemocyte function in a Galleria mellonella infection model [10]. Likewise, since $A s$ pergillus fumigatus is another biofilm-producing fungus, acetylcholine would protect against Aspergillus infection by inhibiting biofilm formation and yeast-to-hyphae transition. A previous study has suggested that $C$. albicans possesses putative cholinergic receptor genes [11], and pharmacological evidence suggests that this organism may possess a receptor that is homologous to human muscarinic receptors [12]. The acetylcholinesterase enzymatic activity inhibited by the neostigmine and partly physostigmine has been found in extracts from mycelium of aspergillus fungus [8]. Therefore, it can be speculated that Aspergillus also may possess putative muscarinic cholinergic receptor. If so, the high doses of atropine and glycopyrrolate which were given for the prolonged period to the patient in the present report may have been able to block the muscarinic receptor in Aspergillus, thus eliminating the acetylcholine-induced protection against biofilm formation. Pathogenic fungi have the capacity to form biofilm structures that are notoriously unresponsive to anti-fungal therapies. Fungal biofilms are located all over the human host, including the upper and lower airways as well as the gastrointestinal and genitourinary tracts [13]. Thus, it must have been detrimental to lose the capacity to inhibit biofilm formation, particularly in this patient of the present report who had a history of diabetes mellitus. Invasive primary colonic aspergillosis, which had been complicated by multiple colon perforations, has been reported in the immunocompetent host without classical risk factors except for diabetes mellitus [14]. Since neutrophil-mediated innate immunity is the first line of host defense against the invasive aspergillosis and neutrophil function is impaired in diabetic patients [15], diabetes mellitus has been considered as an important risk factor for invasive aspergillosis. In the present case, diabetes mellitus may have contributed to the development of enteroinvasive aspergillosis in part.

Platelet count was very high just before the first laparotomy. Platelets bind plasma-opsonized hyphae and degranulate. The interaction of platelets with hyphae re- 
sults in reduced hyphal galactomannan release [16]. This antifungal activity of human platelets against Aspergillus species may explain the negative result of galactomannan test, which was done right after the first surgery, despite extensive invasion of small intestine by Aspergillus infection. Interestingly, platelet count was not elevated around the second surgery. According to a previous study [17], a galactomannan index cutoff value $\geq 2.0$ is able to classify patients with a poor outcome in the invasive aspergillosis with a sensitivity of $100 \%$. As such, the repeated galactomannan test right after second surgery, which was 5.42 index, predicted an inevitable poor outcome in the present case.

The mainstay of treatment for organophosphate poisoning includes administration of atropine and mechanical ventilatory support. Reactivation of inhibited acetylcholinesterase may improve clinical pictures. Oximes retard the acetylcholinesterase aging rate. However, acetylcholinesterase aging (loss of alkyl side chain that prevents reactivation by oximes [18]) is particularly rapid with dimethyl phosphoryl compounds such as methidathion and may thwart the effective reactivation by oximes, particularly in excessive dose. In methidathion poisoning, therefore, it seems that there is no point to keep maintaining oxime after the initial dose. Removal of organophosphate from body, such as gastric lavage and hemoperfusion, may be another way to improve clinical pictures. According to the previous report [19], hemoperfusion was ineffective and did not provide real clinical benefit to the patient. Because of relatively high fat solubility and hence a large apparent volume of distribution, hemoperfusion could remove only small portion of methidathion. Also, there was evidence that the redistribution of methidathion from fat to blood could take place when plasma level diminished [19]. In contrary, gastric lavage with bicarbonate may provide some benefits, because the toxicity of organophosphates is reduced in an alkaline medium. Methidathion is stable in a neutral or a weak acid medium, but hydrolyzed in an alkaline medium [20]. The patient had had a depolarizing block even more than 5 weeks after the ingestion of methidathion.
Depolarizing block is an endplate-muscular block (phase I), from which the block will gradually change into a desensitizing phase II neuromuscular block, as the patient recovers.

It appears that the long-lasting profound hypotension, requiring high doses of vasoconstrictors and inotropes caused the fatal enteroinvasive Aspergillus fungal infection in the present case with methidathion poisoning. The profound hypotension lead to splanchnic ischemia, the use of high doses of inotropes stimulated biofilm formation by Aspergillus fungus, and parasympatholytic drugs eliminated the acetylcholine-induced protection against biofilm formation. With the history of diabetes mellitus in this patient, the fatal outcome from secondary infection of biofilm-forming organism may have been inevitable.

\section{References}

1. Bull DL. Metabolism of O, O-dimethyl phosphorodithioate S-ester with 4-(mercapto-methyl)-2methoxy- $\Delta 2-1,3,4$-thiadiazolin-5-one (Geigy GS13005) in plants and animals. J Agric Food Chem 1968;16:610-16.

2. Reilly PM, Bulkley GB. Vasoactive mediators and splanchnic perfusion. Crit Care Med 1993;21(2 Suppl):S55-68.

3. Tokyay R, Zeigler ST, Traber DL, Stothert JC Jr, Loick HM, Heggers JP, et al. Postburn gastrointestinal vasoconstriction increases bacterial and endotoxin translocation. J Appl Physiol (1985) 1993;74:1521-7.

4. Freestone PP, Hirst RA, Sandrini SM, Sharaff F, Fry H, Hyman S, et al. Pseudomonas aeruginosacatecholamine inotrope interactions: a contributory factor in the development of ventilator-associated pneumonia? Chest 2012;142:1200-10.

5. Lyte M, Freestone PP, Neal CP, Olson BA, Haigh $\mathrm{RD}$, Bayston R, et al. Stimulation of Staphylococcus epidermis growth and biofilm formation by catechol- 
amine inotropes. Lancet 2003;361:130-5.

6. Eisendle M, Oberegger H, Zadra I, Haas H. The siderophore system is essential for viability of Aspergillus nidulans: functional analysis of two genes encoding 1-ornithine $\mathrm{N} 5$-monooxygenase (sidA) and a non-ribosomal peptide synthetase (sidC). Mol Microbiol 2003;2:359-75.

7. Rosas-Ballina M, Olofsson PS, Ochani M, ValdésFerrer SI, Levine YA, Reardon C, et al. Acetylcholine-synthesizing $\mathrm{T}$ cells relay neural signals in a vagus nerve circuit. Science 2011;334:98-101.

8. Roshchina VV, Aleksandrova IF. An enzyme from the fungus Aspergillus niger that hydrolyzes choline ethers. Nauchnye Doki Vyss Shkoly Biol Nauki 1991;12:50-4.

9. Fiddian-Green RG, Haglund U, Gutierrez G, Shoemaker WC. Goals for the resuscitation of shock. Crit Care Med 1993;21(2 Suppl):S25-31.

10. Rajendran R, Borghi E, Falleni M, Perdoni F, Tosi D, Lappin DF, et al. Acetylcholine protects against Candida albicans infection by inhibiting biofilm formation and promoting hemocyte function in a Galleria mellonella infection model. Eukaryot Cell 2015;14:834-44.

11. Inglis DO, Arnaud MB, Binkley J, Shah P, Skrzypek MS, Wymore F, et al. The Candida genome database incorporates multiple Candida species: multispecies search and analysis tools with curated gene and protein information for Candida albicans and Candida glabrata. Nucleic Acids Res 2012;40(Database issue):D667-74.
12. Borghi E, Morace G, Borgo F, Rajendran R, Sherry J, Nile C, et al. New strategic insights into managing fungal biofilms. Front Microbiol 2015;6:1077.

13. Ramage G, Robertson SN, Williams C. Strength in numbers: antifungal strategies against fungal biofilms. Int J Antimicrob Agents 2014;43:114-20.

14. Cha SA, Kim MH, Lim TS, Kim HH, Chang KY, Park HS, et al. Invasive primary colonic aspergillosis in the immunocompetent host without classical risk factors. Yonsei Med J 2015;56:1453-6.

15. Delamaire M, Maugendre D, Moreno M, Le Goff MC, Allammic H, Genetet B. Impaired leukocyte function in diabetic patients. Diabet Med 1997;14:29-34.

16. Lass-Flörl C, Roilides E, Löffler J, Wilflingseder, Romani L. Minireview: host defence in invasive aspergillosis. Mycoses 2013;56:403-13.

17. Russo A, Giuliano S, Vena A, Lucidi C, Falcone M, Raponi G, et al. Predictors of mortality in nonneutropenic patients with invasive pulmonary aspergillosis: does galactomannan have a role? Diagn Microbiol Infect Dis 2014;80:83-6.

18. Eyer P. The role of oximes in the management o organophosphorus pesticide poisoning. Toxicol Rev 2003;22:165-90.

19. Zoppellari R, Targa L, Tonini P, Zatelli R. Acute poisoning with methidathion: a case. Hum Exp Toxicol 1990;9:415-9.

20. Nelson DL, Crawford CR. Organophosphorus compounds; the past and the future. Clin Toxicol 1972;5:223-30. 